Persp. Teol. 41 (2009) 59-70

\title{
A COMPANHIA DE JESUS E O APOSTOLADO SOCIAL (1946-1975)
}

(The Society of Jesus and the social apostolate - 1946-1975)

Grimaldo Carneiro Zachariadhes *

RESUMO: O presente artigo pretende abordar a importância que o apostolado social começou a ter para a Companhia de Jesus, especialmente a latino-americana, na conjuntura do Pós-2 $2^{a}$ Guerra Mundial. Será analisada a criação dos Centros de Investigação e Ação Social (CIAS) como uma melhor forma de exercer este apostolado. O artigo será finalizado com a promulgação do decreto $4^{\circ}$, em 1975, pela Congregação Geral XXXII, quando a Companhia de Jesus oficializará a luta pela Justiça Social como uma missão de todos os jesuítas.

PALAVRAS-CHAVE: Companhia de Jesus, Apostolado social, Jesuítas, Justiça social, Igreja Católica.

ABSTRACT: This article intends to analyze the importance that the Social apostolate began to have for Society of Jesus, especially in Latin America, in the conjuncture after Second World War. It will be analyzed the creation of the Centers of Investigation and Social Action as a better form of exercising this apostolate. The article will be concluded with the promulgation of the ordinance $4^{\circ}$, in 1975, for the General Congregation XXXII, when Society of Jesus will make official the fight for the Social Justice as a mission of all the Jesuits.

KEY-WORDS: Society of Jesus, Social apostolate, Jesuits, Social justice, Catholic Church.

\footnotetext{
* Centro de Estudos e Ação Social (CEAS) de Salvador - BA. Artigo submetido a avaliação no dia 26/05/2008 e aprovado para publicação no dia 13/10/2008.
} 


\title{
Introdução
}

\begin{abstract}
A partir do Pós-2 ${ }^{a}$ Guerra Mundial, a Igreja Católica Romana iniciou A um período de atualização ao mundo moderno e começou a passar por uma grande transformação. Esse processo foi acelerado com o Concílio Ecumênico Vaticano II que legitimou certas tendências modernizadoras dentro da Igreja Católica. Esse processo de atualização ao mundo moderno feito pela Igreja é conhecido como aggiornamento e contou com o apoio dos Papas João XXIII e Paulo VI. As Ordens religiosas não ficaram imunes a esse período de transformações e também refletiram esse processo em suas práticas.
\end{abstract}

A Companhia de Jesus, Ordem fundada por Inácio de Loyola no século XVI, também passou por grandes mudanças nesse momento. Estimulados pelos Superiores Gerais João Batista Janssens e depois Pedro Arrupe, os inacianos em todo o mundo, com a intenção de aumentar sua influência dentro da sociedade, se comprometeram mais com os problemas do seu tempo. A partir principalmente da segunda metade do século XX, os jesuítas começaram a priorizar em seu trabalho apostólico as questões sociais. Os inacianos viam os problemas sociais como um empecilho para a evangelização da sociedade e por isso trabalharam para ajudar a solucionálos.

O conflito entre o Trabalho e o Capital, as desigualdades cada vez maiores entre os países ricos e os países pobres, a miséria que parcelas significativas da população mundial estavam vivendo mesmo com o crescimento econômico de várias nações e o agravamento dos conflitos sociais em algumas regiões fez com que setores da Companhia de Jesus repensassem sua práxis e assumissem um compromisso mais forte com o intuito de transformar as estruturas econômicas para tornar o mundo mais justo.

\section{Os jesuítas se voltam para a América latina}

Quando terminou a Segunda Grande Guerra Mundial (1939-1945), a Europa tinha perdido definitivamente o seu protagonismo para os Estados Unidos. Também surgiria, a partir daquele momento, uma nova potência, a União das Repúblicas Socialistas Soviéticas (URSS) e com isso deixando sempre presente ao mundo capitalista o "perigo vermelho". Os horrores da Guerra abalaram dogmas racistas de superioridades e revelaram a fragilidade de um conceito estreito de Civilização. Começaram também as lutas pela independência das colônias na Ásia e África contra as metrópoles europeias que saíram enfraquecidas da Guerra. O surgimento de novas Nações mostrava à Igreja Católica uma distância enorme entre ela e as aspirações destes novos povos. Era preciso repensar o seu papel diante 
dessa nova realidade que se apresentava e se adaptar a esse novo mundo. E uma região, a América Latina, mereceu destaque para a Cúria Romana, ainda mais depois da Revolução Cubana (1959). Para José Oscar Beozzo, "Cuba é um divisor de águas na vida do continente latino-americano e também questão crucial para a Igreja"1.

Entretanto, é necessário lembrar que a América Latina, desde o século XIX, tinha começado a ter uma importância cada vez maior para o Vaticano. Tinha sido criado o colégio Pio Latino-americano, em Roma, em 1858 para a formação do clero na região. Em 1934, foi construído o Pio Brasileiro separado do Latino-americano. Porém, foi a partir do Pós- $2^{a}$ Guerra Mundial que ocorreu uma atenção renovada por parte da Cúria Romana pela região. O Papa Pio XII apoiou a criação, em 1955, do CELAM - Conselho Episcopal Latino-americano - para organizar o episcopado da América Latina. Os problemas do continente latino-americano começaram a ser analisados pela CAL (Pontifícia Comissão para a América Latina), fundada em 1958, que tinha como função promover uma maior cooperação entre a Cúria romana e as Igrejas nacionais na procura de soluções para os problemas do continente. Em 1959, foi fundada a CLAR - Conferência LatinoAmericana de Religiosos - para reunir as Ordens religiosas.

O continente latino-americano também se tornou alvo das preocupações da Companhia de Jesus, que recebeu como missão dada pelo próprio Vaticano, uma maior atenção na evangelização dos povos da América Latina, como percebemos em uma carta de um provincial italiano:

Nosso M. R. Padre Geral me tornava presente as graves condições dos fiéis na América Latina e a insistência da Santa Sé para que, deixando mesmo outras obras existentes na Europa, se procurasse atender à lastimável falta de clero e às espirituais necessidades dos fiéis carentes da devida defesa contra as insídias do protestantismo, do comunismo, do liberalismo e da maçonaria ${ }^{2}$.

Atendendo a essa nova conjuntura, no final da década de 40, o Prepósito Geral da Companhia de Jesus, João Batista Janssens, enviou o padre Tomáz Travi para visitar as províncias jesuíticas na América Latina, que o informou dos graves problemas que muitas delas passavam, principalmente devido à escassez de religiosos. Em 1952, o Superior dos Jesuítas desmembrou duas províncias jesuíticas do Brasil para um melhor trabalho apostólico. A província do Brasil Central foi dividida e criada a vice-pro-

\footnotetext{
${ }^{1}$ J.O. BEOZZO, A Igreja do Brasil: de João XXIII a João Paulo II, de Medellín a Santo Domingo, Petrópolis: Vozes, 1993, p. 19.

2 "Carta do Padre Pietro Costa aos Membros da província Vêneto-Milanesa da Companhia de Jesus", 24/05/1954, in J.M. RUIZ Y SÁNCHEZ DE CUETO, Raízes de uma Missão: Dados para uma história da província da Bahia da Companhia de Jesus, Salvador, 2002, pp. 18-19.
} 
víncia Goiano-Mineira formada pelos estados de Minas Gerais, Espírito Santo e Goiás; e a vice-província do Brasil Setentrional foi dividida e criada a imensa vice-província da Bahia, integrada pelos estados da Bahia, Maranhão, Piauí, Pará, Amazonas, Acre, Amapá e o antigo território Rio Branco (hoje estado de Roraima). Essas duas vice-províncias recém-criadas ficariam dependentes de províncias europeias que teriam a obrigação de enviar religiosos para ajudar nos trabalhos apostólicos ${ }^{3}$.

Em um balanço da ação apostólica da Companhia de Jesus na primeira metade do século XX, o jesuíta João Augusto A. A. Mac Dowell afirmou que "[n]o conjunto da ação apostólica dos jesuítas nos primeiros cem anos desde seu regresso ao Brasil até meados do século XX, ressalta, em primeiro lugar, o apostolado educativo" ${ }^{\prime 4}$. Porém, isso começaria a mudar. Setores da Companhia de Jesus começaram a repensar a sua atuação no mundo e procuraram se adaptar à nova conjuntura que se abria depois da $2^{\mathrm{a}}$ Guerra Mundial. A partir daí, um outro apostolado começou a ganhar força: o apostolado social. A Companhia de Jesus tanto a nível internacional como nacional começava a discutir mais profundamente a Questão Social e a perceber que a educação, como todos os outros ministérios, deveria ser estudado e planejado em paralelo com os problemas sociais.

\section{A Companhia de Jesus e a Questão Social}

O historiador britânico Eric Hobsbawm, ao fazer a história do século XX, afirmou que o período de 25 a 30 anos após a Segunda Guerra Mundial foi de "extraordinário crescimento econômico e transformação social, anos que provavelmente mudaram de maneira mais profunda a sociedade humana que qualquer outro período de brevidade comparável". Este período de crescimento econômico, ele afirmou que era visto como uma "Era de Ouro". Porém, Hobsbawm fez questão de lembrar que essa "Era de Ouro pertenceu essencialmente aos países capitalistas desenvolvidos" que durante esse período representaram "cerca de três quartos da produção do mundo, e mais de $80 \%$ de suas exportações manufaturadas". Isso não impediu que

\footnotetext{
${ }^{3} \mathrm{Em}$ 1973, foram reintegrados os estados do território da vice-província Goiano-Mineira à província do Brasil Central e criada a Província do Brasil Centro-Leste. Em 2005, as províncias da Bahia e a vice-província Setentrional se juntaram formando a província do Brasil Nordeste. Existem ainda no País os seguintes territórios da Companhia de Jesus: a província Brasil Meridional (Rio Grande do Sul, Santa Catarina, Paraná, Mato Grosso e Rondônia) e o Distrito da Amazônia (Pará, Amazonas, Roraima, Amapá e Acre).

${ }^{4}$ J.A.A.A. MAC DOWELL, "Companhia de Jesus - 450 anos a serviço do povo brasileiro", in C. BRESCIANI (org.), Companhia de Jesus - 450 anos a serviço do povo brasileiro, São Paulo: Loyola, 1999, p. 229.
} 
alguns países capitalistas periféricos crescessem visivelmente, embora "a riqueza geral jamais chegasse à vista da maioria da população do mun$\mathrm{do}^{\prime \prime}$.

Foi um período de grande crescimento econômico do mundo capitalista, porém de forma desigual entre as Nações desenvolvidas e as chamadas de Terceiro mundo. E isso foi destacado por vários setores da Igreja Católica. Quando em 1891, o Papa Leão XIII tinha se manifestado sobre a Questão Social com a encíclica Rerum Novarum, o horizonte dele era a Europa e a sua preocupação era com "a condição dos operários", o conflito de que se tratava naquele documento era entre o Capital e o Trabalho. Porém, no meado do século XX, a Questão Social para a Igreja tinha se ampliado e incluído também o desenvolvimento desigual entre as Nações. O Papa João XXIII, em uma encíclica, deixava isso claro:

O maior problema da época moderna talvez seja o das relações entre as comunidades políticas economicamente desenvolvidas e as que se encontram em fase de desenvolvimento econômico. As primeiras, por conseguinte, com alto nível de vida, as outras, em condições de escassez ou de miséria [...] [D]ada a interdependência cada vez maior entre os povos, não é possível que entre eles reine uma paz durável e fecunda, se o desnível das condições econômicas for excessivo ${ }^{6}$.

Nesse período de grandes transformações por que passava o mundo, sob o espectro da Guerra Fria, o Papa João XXIII (1958-63) estimulou o processo conhecido como aggiornamento da Igreja Católica. As encíclicas Mater et Magistra (1961) e Pacem in Terris (1963) de João XXIII modificaram o pensamento oficial. Começou a se defender uma nova concepção de Igreja, mais em sintonia com o mundo secular, comprometida em melhorar o destino dos seres humanos na Terra e em promover a Justiça Social. Essa tendência foi ratificada com o Concílio Ecumênico Vaticano II (1962-65), que foi o evento mais importante do catolicismo romano no século $\mathrm{XX}^{7}$. Quando João XXIII faleceu, em 1963, o Papa Paulo VI (1963-78) continuou esse processo de atualização e de abertura da Igreja Católica ao mundo contemporâneo, enfatizando sempre a defesa da Justiça Social.

Desde o pós- $2^{\text {a }}$ Guerra, a Questão Social começou a ter um peso muito grande na Companhia de Jesus. Apesar de em outras Congregações Ge-

\footnotetext{
${ }^{5}$ E. HOBSBAWM, A Era dos Extremos, São Paulo: Companhia das Letras, 1994, pp. 15 e 255 .

${ }^{6}$ JOÃO XXIII, Mater et Magistra, São Paulo: Paulinas, 1961, p. 52.

${ }^{7}$ Sobre o Vaticano II e a sua importância para a Igreja Católica, ver, entre outros, J.O. BEOZZO, A Igreja do Brasil: de João XXIII a João Paulo II, Petrópolis: Vozes, 1993, e P.S.L. GONÇALVES / V.I. BOMBONATTO (orgs.), Concílio Vaticano II - Análise e prospectivas, São Paulo: Paulinas, 2004.
} 
rais $^{8}$ a Companhia de Jesus já ter se ocupado das questões sociais, foi com a Congregação Geral XXIX, de 1946, que o apostolado social começou a ter uma maior importância para esta Ordem religiosa ${ }^{9}$. Nesta Congregação se retomou um ponto da anterior que estabelecia como uma forma melhor de os jesuítas trabalharem para enfrentar os problemas sociais, que se instituísse, em cada província ou região, um "Centro de estudos e ação sociais". Esse Centro tinha que estar "apto para estender e propagar o trabalho social, impulsionar e dirigir a Ação social dos nossos"10.

A Companhia de Jesus apoiará a criação dos CIAS - Centros de Investigação e Ação Social - como uma forma de melhor exercer o apostolado social. Os CIAS tinham como objetivo difundir a Doutrina Social da Igreja e também ser um local de reflexão sobre as questões sócio-econômicas de um determinado lugar e que tentava ajudar os inacianos (e a sociedade) na superação dos problemas mostrando as causas e os meios para isto.

Os Prepósitos Gerais João Batista Janssens (1946-1964) e depois Pedro Arrupe (1965-1983) intensificaram sua atenção para o apostolado social, exigindo que as províncias dos jesuítas em todo o mundo começassem a dar uma maior atenção aos problemas que dificultavam a missão evangelizadora da Companhia e que cada uma criasse o seu CIAS. O Padre Geral João Batista Janssens escreveu um documento chamado Instrução sobre o Apostolado Social (1949) que teve grande repercussão na Companhia de Jesus, pois era a primeira vez que um Superior dos Jesuítas se dirigia a toda a Ordem sobre este tema ${ }^{11}$. Esse documento era um alerta e um chamado à ação dos jesuítas para enfrentarem a nova realidade que se apresentava.

Neste documento, o Superior da Companhia identificava os dois grandes inimigos do povo cristão: o comunismo ateu e o liberalismo que se fundamentava no egoísmo e na cobiça desenfreada. A Companhia de Jesus, preocupada com as condições de pobreza dos trabalhadores e também com a influência dos comunistas nos mesmos, ajudou a formular um pensamento social católico. O clero procurava construir uma alternativa para o socialismo e para o liberalismo econômico que era visto também como um mal e responsável pela penúria dos trabalhadores ${ }^{12}$.

\footnotetext{
${ }^{8}$ A Congregação Geral é a instância máxima da Companhia de Jesus. Reúne todos os provinciais, os assessores da Cúria generalícia e alguns padres eleitos para eleger o Prepósito Geral e/ou legislar sobre a missão apostólica e religiosa da Companhia.

9 Jesuítas - Anuário da Companhia de Jesus 2000, p. 11.

${ }^{10}$ As Congregações Gerais. (Mimeografado - Sem numeração das páginas).

${ }^{11}$ Essa Carta é tão significativa para a Companhia de Jesus com relação ao apostolado social que os jesuítas Michael CZERNY e Paolo FOGLIZZO colocam, a partir deste documento, como marco de uma nova fase da Companhia de Jesus com relação à Questão Social. In Jesuítas - Anuário da Companhia de Jesus 2000, p. 103.

${ }_{12}$ Apesar deste combate virulento aos comunistas neste momento, mais tarde, setores importantes da Companhia de Jesus procuraram um diálogo com eles. Para o diálogo de
} 
Na sua Instrução, o Geral Janssens falava da mísera condição espiritual e material dos trabalhadores e avisava: "Levantemos os olhos e encaremos à luz da verdade o que estamos vendo todos os dias e a que, infelizmente, nos acostumamos e tornamos indiferentes". O Prepósito fez questão de diferenciar que quando falava de apostolado social, não era no sentido tradicional de ajuda aos velhos e órfãos que sem poder buscar os meios de subsistência necessitavam de caridade, esse tipo de ação ele denominou de "caridade extraordinária". Mas o que ele queria era "falar dos pobres que têm forças para ganhar honestamente seu sustento, e não podem, vista a imperfeita ordem social destes tempos, prover a si e aos seus como convém".

Ele definia a finalidade do apostolado social, como "dar ao maior número possível, e mesmo a todos os homens, enquanto a condição terrena o permite, certa abundância ou pelo menos mediana dos bens, tanto temporais como espirituais, mesmo na ordem natural". E para isso era preciso que os jesuítas estivessem mais próximos dos pobres e "sentir o que seja viver a vida inteira humilhado; permanecer em ínfima condição; ser esquecido e desprezado [...] ser o instrumento por meio do qual outros se enriquecem". Ele lembrava que todos os ministérios da Companhia (Colégios, Congregações Marianas, Exercícios Espirituais, Missões entre outros) deveriam estar ligados à Questão Social, porém deveria existir o que ele chamava de um "apostolado social especializado". E para isso, ele retomava a questão da criação dos Centros de Informação e Ação Social que tinham como finalidade principalmente

[e]nsinar aos outros a doutrina teórica e prática, de modo particular aos sacerdotes, aos leigos cultos e aos mais adiantados dentre os operários, ajudando-os com sua orientação. Esse "Centro", como já se faz em muitos lugares, difundirá a doutrina social da Igreja por meio de livros, revistas, artigos, conferências e aulas, congressos e quaisquer outros meios, e se esforçará por adaptá-los às necessidades de cada região ${ }^{13}$.

João Batista Janssens enviou o padre Manuel Focaya para a América Latina com o intuito de fomentar o apostolado social no continente. $\mathrm{O}$ padre Focaya lembrava aos inacianos que na economia capitalista milhares de trabalhadores viviam na miséria, então, "a mera assistência social não resolve o problema social de nossa época. É preciso ir à raiz, arrancando na sua origem a injustiça". E, para isso, ele recordava as palavras do Superior

setores da Companhia de Jesus no Brasil com o marxismo, ver: G.C. ZACHARIADHES, "CEAS: Jesuítas e o Marxismo", in M.C.L. BINGEMER / I. NEUTZLING / J.A.A.A. MAC DOWELL (orgs.), A Globalização e os Jesuitas: Origens, história e impactos. Anais do Seminário Internacional (25 a 29 de setembro de 2006), vol. 2, São Paulo: Loyola, 2007, pp. 101-114.

${ }_{13}$ J.B. JANSSENS, Instrução sobre o Apostolado Social, 1949, pp. 5-30. 
dos jesuítas para quem todos os ministérios da Companhia de Jesus deveriam trabalhar para ajudar a resolver os problemas sociais. Mas, ele retomava a questão da criação dos CIAS e lembrava que o "apostolado social direto" deveria ter "padres que se entreguem por completo a este ministério"14.

No Brasil, a partir da década de 60, seriam criados os seguintes CIAS para auxiliar os inacianos a enfrentarem os problemas sociais graves que existiam no País: o Centro de Investigação e Análise Social João XXIII, no Rio de Janeiro, onde funcionava também o Instituto Brasileiro de Desenvolvimento (IBRADES); o Centro de Estudos e Ação Social (CEAS), na Bahia; e o Centro de Documentação e Pesquisa (CEDOPE) na cidade de São Leopoldo, no Rio Grande do Sul ${ }^{15}$.

\section{A Missão da Companhia de Jesus: Defesa da Fé e Promoção da Justiça Social}

Quando Pedro Arrupe se tornou Prepósito Geral da Companhia de Jesus, em 1965, ele também continuou incentivando um envolvimento maior dos jesuítas com as questões sociais. Ele deu uma atenção especial para a América latina. Com o seu apoio, o apostolado social foi ganhando cada vez mais importância para a Companhia de Jesus. No continente latinoamericano, ele prosseguiu apoiando a criação dos CIAS e seu fortalecimento. Estimulou a fundação, em 1966, de um Conselho que congregasse os CIAS da América Latina e fosse um elo com o Padre Geral, o CLACIAS Conselho Latino-americano dos CIAS. Em uma carta endereçada a todos os padres dos CIAS latino-americanos, ele deixava clara a sua posição em relação ao apostolado social: "nenhum de vocês deveria duvidar da vontade da Companhia, nem de que eu pessoalmente me identifico com quem dê prioridade ao apostolado da justiça social, nas circunstâncias concretas da América Latina"16.

Apesar do crescimento econômico de alguns países da América Latina, a pobreza era gritante entre a maioria da população do continente. Essa contradição foi denunciada pela Companhia de Jesus. Entre os dias 6 e 14

\footnotetext{
${ }^{14}$ M. FOYACA, "Instrução", in COMPANHIA DE JESUS, Pastoral popular - Fundamentação inaciana, São Paulo: Loyola, 1991, pp. 115-142.

${ }^{15}$ Infelizmente não existe nenhum trabalho acadêmico que aborde a história do CEDOPE ou do Centro Social João XXIII. Sobre a fundação do CEAS e a sua importância para a sociedade brasileira, ver minha dissertação: G.C. ZACHARIADHES, CEAS: Jesuittas e a Questão Social durante a Ditadura Militar, Salvador: UFBA, 2007.

16 "[N]inguno de ustedes debería dudar de la voluntad de la Compañía, ni de que yo personalmente me identifico con quien dé prioridad al apostolado por la justicia social, en las circunstancias concretas de América Latina". Carta A todos los Padres miembros de los CIAS de América Latina, 12/12/1966.
} 
de maio de 1968, Pedro Arrupe esteve reunido com os provinciais da América Latina, no Rio de Janeiro, para discutir as questões sociais do continente. Desse encontro saiu a Carta do Rio ou Carta da Gávea, como também é conhecida. Esse documento é muito importante para a Companhia latino-americana, pois nele foram analisados os problemas que a América Latina estava passando no período por uma ótica local. Colocavase a questão do crescimento acelerado do continente, mas a continuação da situação de miséria da maior parte dos habitantes, a questão das populações urbanas e rurais marginalizadas e também a "discriminação racial" que sofriam "as populações indígenas" ${ }^{17}$.

Lembrava-se que "o problema social da América Latina é o problema do próprio homem", então, a Questão Social tinha que ter uma prioridade absoluta na estratégia apostólica dos jesuítas e todos os outros apostolados, dando ênfase à educação, deveriam estar integrados ao apostolado social.

Desejamos que todas as formas de apostolado da Companhia, sem perder seu fim específico, se integrem no apostolado social.

No que diz respeito à educação, que julgamos ser um dos fatores principais de transformação social, afirmamos a urgência de que nossos colégios e universidades aceitem seu papel de agentes eficazes da integração e da Justiça Social na América. O desenvolvimento de todos não será possível sem a educação integral de todos ${ }^{18}$.

A Carta do Rio recordava aos jesuítas que "em toda nossa ação, o objetivo deve ser a libertação do homem de qualquer forma de escravidão que o oprime: a falta de recursos mínimos e de alfabetização, o peso das estruturas sociais". Lembrava que durante anos já estavam sendo fundados os Centros de Investigação e Ação Social nas províncias da América Latina, cuja missão específica era "ajudar a conscientizar, estimular e orientar as mentalidades e as ações, com investigações, publicações, ensino e assesso-

\footnotetext{
${ }^{17}$ É importante notar esta menção aos povos indígenas nas preocupações da Companhia de Jesus latino-americana neste momento, pois, quando, alguns meses depois deste encontro dos jesuítas, ocorrer, em Medellín, na Colômbia, a II Conferência Episcopal Latino-americana, os índios não serão contemplados diretamente, conforme constatou o padre José Oscar BEOZZO: "Medellín não consagrou nenhum de seus documentos e de suas análises às populações indígenas do continente entre as mais espoliadas, exploradas e agredidas física, cultural e espiritualmente" (J.O. BEOZZO, A Igreja do Brasil: de João XXIII a João Paulo II, de Medellín a Santo Domingo, p. 126).

${ }^{18}$ Segundo o jesuíta Gabriel CODINA, "[a] Carta do Rio não se deteve unicamente na teoria. Nossos colégios [...] tomaram a sério o 'serviço social' proposto no Rio [...] Num momento de sério questionamento das nossas instituições educativas, dentro e fora da Companhia, estes aceitaram o desafio de uma nova conversão, comprometeram-se na linha de serem fatores de mudança social e descobriram neste compromisso a sua razão de ser" (G. CODINA, "Fé e Justiça nos conteúdos da instituição educativa", in ID., Fé e Justiça Social nos colégios da Companhia de Jesus, Col. Ignatiana no ${ }^{\circ}$ 30, São Paulo: Loyola, 1987, pp. 5-30, aqui p. 7).
} 
ria". Avisava que a Companhia de Jesus ainda tinha que destacar mais homens para estas obras, mas fazia a ressalva de que se tinha era que sempre "responsabilizar os homens do povo para que sejam eles os protagonistas de sua própria libertação"19.

Em um documento de Arrupe para os jesuítas do Brasil, o Superior voltava a insistir na necessidade e urgência de as províncias jesuíticas no País destinarem pessoal para uma reflexão acurada da realidade brasileira e que procurassem ajudar a formular soluções para os problemas sociais graves existentes no Brasil, pois "não se pode já esperar demasiado". O Superior abordava também a questão da educação popular que se deveria realizar com os chamados marginalizados, "jovens e adultos, tão numerosos ainda nalgumas regiões, e com os índios, cujas circunstâncias especiais requerem uma atenção, uma solicitude e uma dedicação muito particulares" 20 .

Esses documentos mostravam um engajamento cada vez maior por parte dos jesuítas com a Questão Social e da sua importância cada vez mais significativa dentro dessa Ordem. Para muitos religiosos, tanto quanto para o próprio Superior Geral Pedro Arrupe, os problemas sociais eram percebidos como obstáculos na evangelização e por isso tinham que ser enfrentados e superados. A Companhia de Jesus iria assumir isso oficialmente com o decreto $4^{\circ}$ da Congregação Geral XXXII, de 1975: A Nossa Missão nos dias de hoje: Diaconia da fé e promoção da justiça. O decreto $4^{\circ}$ (como é simplesmente conhecido) é visto pelos jesuítas como o aprofundamento do apostolado social, o ponto culminante do engajamento da Companhia na luta em defesa da Justiça Social.

No decreto $4^{\circ}$ era lembrado que "milhões de homens do nosso tempo sofrem pobreza e fome, uma repartição desigual e injusta dos bens e recursos, e as conseqüências da discriminação social, racial e política!". E avisava que "apesar das possibilidades abertas pela técnica, cada vez mais claramente se vê que o homem não está disposto a pagar o preço duma sociedade mais justa e mais humana", então, o que estava em jogo era "o próprio sentido do homem, do seu futuro e do seu destino". Assim sendo, uma verdadeira evangelização "não se pode realizar a sério sem promoção da justiça". Então,

[a]s desigualdades e injustiças já não podem ser consideradas como resultado dalguma fatalidade "natural"; são antes obra do homem e do seu egoísmo. Não há, por conseguinte, promoção propriamente cristã da justiça integral sem um anúncio de Jesus Cristo e do mistério da reconciliação que

\footnotetext{
19 "Carta dos provinciais da América latina aos Jesuítas latino-americanos", in Anuário da Companhia de Jesus 1968-1969. Edição portuguesa.

${ }^{20} \mathrm{P}$. ARRUPE, "Ad Socios Provinciarum Brasiliae peracta visitatione Patris Generalis (16 apr.-15 maii)”, in Acta Romana Societatis Iesu 15 (1968/no 2) 353-360.
} 
Ele levou a bom termo [...] Inversamente, não há verdadeiro anúncio de Cristo, não há verdadeira proclamação do seu Evangelho, sem compromisso decidido de promover a justiça.

No decreto $4^{\circ}$ estava determinado que "[a] missão da Companhia de Jesus, hoje, é o serviço da fé, do qual a promoção da justiça constitui uma exigência absoluta". Então se chegava ao ponto máximo; a partir daquele momento, a luta pela Justiça Social era uma missão de todos os jesuítas em qualquer parte do mundo, assim como levar a palavra de Deus aos homens. Fé e Justiça Social se tornavam complementares, uma não podia existir sem a outra para nenhum membro da Companhia de Jesus. Anunciar o evangelho de Jesus Cristo exigia um comprometimento firme dos jesuítas em fazer "o mundo diferente do que ele é, e, por conseguinte, sinal do outro mundo" 21 .

Quando se procurou fazer a análise dos documentos da alta hierarquia da Companhia de Jesus sobre a Questão Social, não se quis com isso menosprezar a atuação dos jesuítas de todo o mundo. Antes mesmo do documento do Padre Geral João Batista Janssens sobre o apostolado social, muitos inacianos estavam atuando nas questões sociais. Porém, em uma instituição hierárquica como a Companhia de Jesus, a legitimação de cima é muito importante, pois impulsiona certas tendências como expressou com toda a precisão o cientista político Scott Mainwaring, no seu estudo sobre a Igreja Católica no Brasil: "A mudança iniciou-se a partir da base, mas tomou impulso somente quando foi legitimada pela cúpula"22.

A importância da legitimação da hierarquia fica clara na afirmação do padre Cláudio Perani, ex-coordenador do CEAS - o CIAS baiano -, onde ele demonstrou a importância do decreto $4^{\circ}$ para os jesuítas mais comprometidos com as questões sociais. Ele comentou que o CEAS era muito criticado por alguns jesuítas, que viam nele uma instituição que só abordava os problemas sociais e quase nunca tocava nas questões espirituais. Perani afirma que depois do decreto $4^{\circ}$ essas críticas foram diminuindo progressivamente ${ }^{23}$. Pois, a partir daquele momento, para todo jesuíta, fé e Justiça Social deveriam se tornar faces de uma mesma moeda, pontas de uma mesma cruz.

21 "Decreto $4^{\circ}$ : A Nossa Missão nos dias de hoje: Diaconia da fé e promoção da Justiça", in Congregação Geral XXXII, 1975, pp. 35-67.

${ }^{22}$ S. MAINWARING, Igreja Católica e política no Brasil (1916-85), São Paulo: Brasiliense, 1989, p. 63.

${ }^{23}$ Apud G.C. ZACHARIADHES, CEAS: Jesuitas e a Questão Social durante a Ditadura Militar, p. 33. 


\section{Comentários finais}

A partir do Pós- $2^{\text {a }}$ Guerra Mundial, a Companhia de Jesus se abriu para a sociedade com o intuito de influenciá-la. Os inacianos procuraram ter uma participação mais decisiva no mundo. Porém, a Companhia de Jesus ficou também mais suscetível às transformações por que passava essa sociedade. $\mathrm{O}$ acirramento dos conflitos sociais em vários países fez com que setores da Companhia de Jesus se tornassem mais conscientes da realidade de opressão pela qual passava boa parte da população mundial e assumissem um compromisso mais forte com a intenção de transformar as estruturas econômicas para tornar o mundo mais justo ${ }^{24}$.

O apostolado social foi ganhando cada vez mais importância para os jesuítas nas suas ações, principalmente na segunda metade do século XX. Na América Latina, importantes setores da Companhia de Jesus lutaram para transformar a sociedade, para torná-la mais justa. Eles se envolveram nas questões sociais e políticas do seu tempo, pois entendiam que os problemas sociais eram obstáculos para a realização de uma sociedade verdadeiramente cristã.

Grimaldo Carneiro Zachariadhes é graduado e mestre em História pela Universidade Federal da Bahia (UFBA) e especialista em Educação pela Universidade do Estado da Bahia (UNEB). Trabalha com educação popular junto a Movimentos Sociais ligados à Igreja Católica em Salvador. Pesquisa o Trabalho Social feito pela Companhia de Jesus no Brasil no século XX. Os artigos mais recentes do autor são: "A Cruz versus a Espada: A resistência do CEAS durante a ditadura militar", Cadernos do CEAS 228 (2007) 5781, e "CEAS: Jesuítas e o Marxismo", in M.C.L. BINGEMER et al. (orgs.), A Globalização e os jesuítas: Origens, história e impactos, vol. 2, São Paulo: Loyola, 2007, pp. 101-114.

Endereço: Rua Pedra da Marca, 13 - Federação 40225-260 Salvador - BA

e-mail: grima1@ig.com.br / grimacz@hotmail.com

\footnotetext{
${ }^{24}$ No entanto, dizer que setores da Companhia de Jesus lutaram para tornar a sociedade mais justa, ainda não explica por completo a questão, pois essa luta foi feita de diversas maneiras. Vários fatores (como o diálogo com as ciências humanas, inclusive com o marxismo, as situações históricas de cada país, entre outros) influenciaram como os inacianos deveriam agir. Isso implica dizer que essa "missão" dos jesuítas na luta pela promoção humana foi entendida e praticada de diversas maneiras.
} 